\title{
1 Heterogeneity of discontinuous carbon fibre composites: Damage \\ 2 initiation captured by Digital Image Correlation
}

3

$4 \quad$ K. Johanson, L. T. Harper*, M. S. Johnson, N. A. Warrior

$5 \quad$ * Corresponding author (lee.harper@nottingham.ac.uk)

6 Division of Materials, Mechanics and Structures, Faculty of Engineering,

7 University of Nottingham, NG7 2RD, United Kingdom

$8 \quad$ Tel: $+44(0) 1159513823$

10 Abstract

This paper aims to identify architectural features which lead to damage initiation and failure in discontinuous carbon fibre composites formed from randomly orientated bundles. A novel multicamera digital image correlation system was used to simultaneously view strain fields from opposing surfaces of coupons, in order to map progression of failure.

The highest strain concentrations were found to occur when the ends of fibre bundles aligned in the direction of loading coincided with underlying transverse bundles. The failure plane was observed to grow between a number of strain concentrations at critical features, coalescing sites of damage to create the final fracture surface. Although potential failure sites can be detected at low global strains in the form of strain concentrations, the strain field observed at low applied loads cannot be extrapolated to reliably predict final failure.

\section{Keywords}




\section{$1 \quad 1$ Introduction}

2 Composites utilising discontinuous, long fibre reinforcement offer versatility in mechanical

3 properties with relatively low manufacturing costs [1]. A number of discontinuous deposition

4 processes have been developed, offering the ability to tailor fibre architectures with varying fibre

5 length, bundle size, alignment and fibre volume fraction [2, 3]. The high level of automation

6 offered by these processes reduces manufacturing costs further. However, as with most

7 discontinuous fibre architectures, these materials are heterogeneous at the mesoscale (bundle

8 level), resulting in both inter and intra-component variation. This variability is the largest single

9 factor preventing wider uptake for structural applications within the composites sector.

10 A high level of material variability also complicates the prediction of mechanical properties compared with textiles. Modified Rule of Mixtures techniques and classical laminate theory provide sufficiently accurate global stiffness predictions [4-8] for discontinuous fibre architectures, but these 'smeared' approaches fail to account for the complex failure mechanisms which influence the onset and propagation of damage.

Research into the failure of discontinuous fibre composites tends to focus on the microscale, studying the failure of individual filaments, fibre debonding, cracking of the matrix and subsequent stress redistributions [9]. The stress state at filament ends is commonly determined using analytical shear-lag approaches [10-12] or Finite Element $(F E)$ studies [13, 14], but it is difficult to extend this work to the bundle level because of complex interactions between contacting fibres. FE models have been developed to establish how the micro mechanical behaviour contributes to failures at the meso and macro scale [15-17], indicating that composite failure is influenced by the packing arrangement in the fibre bundle [18].

The failure mode for mesoscale discontinuous fibre composites is therefore complex and is dependent on additional architectural features that result from kinking and interweaving of short fibres within bundles, local alignment of filament ends and inter-bundle resin rich regions[19]. The tensile failure mode is strongly influenced by the bundle aspect ratio, where the damage mechanism can be interpreted in terms of damage zone size. According to [20], damage tends to initiate at large bundles orientated transversely to the loading direction, providing a natural pathway for crack growth. The crack stops or deviates at points where bundles cross, spreading 
across large volumes of material and therefore dissipating high levels of energy. As the bundle aspect ratio reduces (fewer filaments or shorter bundles), the absence of large bundles provides less resistance to crack growth. Crack propagation is unhindered as fibres fracture, producing a relatively smooth failure surface and a much smaller damage zone.

Other studies have shown that large stress concentrations exist at bundle ends [21], as the chopped filaments remain coplanar. This end synchronisation is another significant failure initiator and yields lower failure strengths compared with evenly dispersed filamentised materials [22]. Choi and Takahashi [23] investigated how the failure mode changes as the depth of these stress concentrations increases from the surface of the sample. Microcracks occur at surface-based tensile stress concentrations due to plane stress conditions. These cracks then propagate along the tip of the fibre into the bulk matrix material. The failure mechanism changes to a shear mode however, as the sub-surface depth of the stress concentration increases, leading to interfacial cracks along the fibre/matrix boundary. Work using acoustic emissions investigating the failure initiation in discontinuous carbon fibre moulding compounds has shown that cracks tend to initiate at the specimen surface [24], but that these early cracks do not necessarily feature in the final fracture plane.

Detailed studies of the surface strains can potentially provide an understanding of how the fibre architecture influences damage initiation and propagation [25, 26]. Digital image correlation (DIC) has been developed as a practical and widely accepted method of full field strain measurement [27-31]. Local displacements, and therefore induced strains, can be calculated for a specimen by comparing a succession of images taken over time during mechanical loading. As a 3D method, it has the added benefit of eliminating image-plane displacement gradients and associated errors, commonly experienced with 2D approaches [32].

Whilst the use of this technique is well established, strain fields are typically determined from just one side of the specimen. This is satisfactory for characterising the behaviour of homogeneous, isotropic materials, but clearly differences can exist between the strain fields from the outer surfaces for composites with random fibre architectures. Feraboli et al [33, 34] used DIC to study local strain effects in discontinuous fibre composites and reported that there was no correlation between strain concentrations associated with voids or resin rich areas and 
1 the site of final failure. Critical features in the fibre architecture may have been overlooked,

2 since strain data was only collected from one side of the sample. It is therefore rational to try

3 and use a multi-camera DIC system to observe the strain fields on both sides of the specimen in

4 stereo.

5 DIC systems with multiple cameras have been successfully used in the literature $[35,36]$, but

6 not to view opposing faces of a tensile specimen. Up to 4 cameras were used to determine the

7 properties of unidirectional laminates in [35]. Two cameras were placed either side of

8 specimens to view the thickness of the laminate during a four point bend test, demonstrating the

9 ability to use DIC to identify through-specimen differences in the strain fields of multi-layer

10 laminates.

11 Combinations of different optical techniques, including DIC, infrared thermography and x-ray tomography have also been recently used to investigate damage initiation and propagation in carbon-epoxy woven laminates [26]. It was demonstrated that each technique was better suited to detecting different phenomena, for instance local fibre fracture was captured more reliably by infrared thermography, therefore a combination of techniques may prove more reliable for detecting damage events.

17 The aim of the current paper is to determine if DIC techniques can be used to identify potential failure initiation mechanisms for discontinuous fibre composites, by relating localised strain variations on both sides of the sample to features in the mesoscale fibre architecture, such as bundle ends and resin rich regions. Studies using low-load surface strain maps will be used to determine if the final fracture location can be predicted from such features.

\section{Methodology}

\subsection{Preparation of composite specimens}

Two composite materials were chosen for the experimental work; a discontinuous fibre architecture and a biaxial non-crimp fabric (NCF). The NCF was chosen as an orthotropic 
benchmark for comparison against the quasi-isotropic discontinuous material, to examine how the ply layup sequence influenced the surface strains.

Preforms with a discontinuous fibre architecture were manufactured using the automated Directed Carbon Fibre Preform (DCFP) process [37]. A revolving chopper head randomly deposited carbon tows, cut to $15 \mathrm{~mm}$ lengths from a continuous bobbin of Toray T700 60E 12k.

The head moved across a perforated metal grid, through which a vacuum was drawn, depositing fibres over a $600 \mathrm{~mm} \times 400 \mathrm{~mm}$ region. Fibre was initially deposited following a series of North-South linear paths across the entire area, and then completed by depositing in an East-West direction. Binder was applied along with the fibres and the process was repeated until the desired fibre areal mass was achieved (see Table 1).

For the NCF samples, $400 \mathrm{~mm} \times 300 \mathrm{~mm}$ preforms were created by hand laminating individual plies of 200gsm/PW-BUD/T700SC 12K 50C/0600mm UD CF NCF (supplied by Sigmatex) into a tool. 12 plies were placed at alternating $0^{\circ}$ and $90^{\circ}$ orientations to achieve a target volume fraction of $40 \%$ in a $3 \mathrm{~mm}$ cavity $\left(\mathrm{NCF}_{1}-[0 / 90]_{6}\right)$. A second unbalanced architecture $\left(\mathrm{NCF}_{2}\right)$ was created with the following ply orientations, [0/90,0/90,0/90,0/90,90/0,90/0], achieving a preform where both external plies are in the $0^{\circ}$ orientation. $3 \%$ wt Reichhold Pretex 110 binder was added between plies and the preform was compacted and cured at $120^{\circ} \mathrm{C}$ for 5 minutes to stabilise.

All preforms were consolidated in a press before being punch cut to fit the $400 \mathrm{~mm} \times 300 \mathrm{~mm}$ Resin Transfer Mould (RTM) tool. Both NCF and DCFP preforms were injected with Huntsman XU3508 resin in a vacuum assisted closed mould tool. The resin was preheated to $80^{\circ} \mathrm{C}$ and the tool temperature maintained at $90^{\circ} \mathrm{C}$ during the 15 minute injection cycle, at pressures of up to 5 Bar. Plaques were then cured for 4 hours at $110^{\circ} \mathrm{C}$ before being removed from the press and air cooled for 2 hours. Five plaques were created in total, with the target thicknesses and volume fractions presented in Table 1.

Dog bone samples were milled from the completed composite plaques (Figure 1), using a gauge width of $38 \mathrm{~mm}$ to avoid problems with material size effects [38]. A stochastic speckle pattern was applied on the front and rear faces using water based paint. Care was taken at this stage to optimise the size and distribution of the pattern to ensure image data was being 
collected across the whole region of interest for the duration of the test. A pattern too fine or too coarse can result in data being lost across the sample. Each specimen had a horizontal line drawn perpendicular to the sample edge, across the width of each surface. This was used during the post processing phase to align the coordinate system within the software to that of the actual specimen and was designated the $\mathrm{X}$-axis. (The direction of tensile elongation was defined as the $\mathrm{Y}$-axis).

\subsection{Multi-camera cluster DIC}

\subsubsection{System development}

Full field strains were measured using a Dantec Dynamics Digital Image Correlation System (Figure 2). The system consisted of four 5.0 Megapixel CCD cameras with $28 \mathrm{~mm}$ lenses. In a conventional 2 camera Digital Image Correlation (DIC) system, one camera is typically used as a reference. Points from images taken by the reference camera are defined on a grid basis and discretised into facet subsets. These facets can then be identified within subsequent images, from the same or a second camera, and their new position identified relative to the reference. A limitation to this approach is that it is only possible to measure the displacement on surfaces which are within view of the reference camera.

A cluster based approach has therefore been developed for conducting a multi camera analysis on two opposing sides of a tensile specimen. The points evaluated using this method were not defined by a reference camera image, but by a virtual object, created from the convergence of images from the various cameras involved. Elimination of the reference image allowed cameras to be positioned to view different areas of the test specimen, with the limitation that at least 2 cameras need to have visibility of the same region for analysis. The cameras also needed to be rigidly mounted to prevent relative movement with each other. A bespoke double sided calibration target was required for the four cameras, with each side of the target having its own unique coordinate system for correlation. By knowing the relative positions of these two coordinate systems a single coordinate system was defined and used for the analysis of the specimen. 


\subsubsection{DIC System settings}

In order to optimise system settings, a sensitivity analysis was conducted on the tensile modulus of high strength rolled steel samples $(200 \times 50 \times 3 \mathrm{~mm})$. The study investigated the effect of gauge length (rectangular gauges $120 \times 38 \mathrm{~mm}$-large, $50 \times 38 \mathrm{~mm}$-small), facet overlap (5,

59 and 12 pixels for a facet size of 17 pixels square) and specimen side (Surface 1, Surface 2).

Stress-Strain curves were created by plotting the average strain values from the two sides of

the specimen against engineering stress. The width and thickness of each specimen was measured with a Vernier calliper in 3 places and the average value used in calculations. The

Young's modulus values were calculated using strains between $1-3 k \mu \varepsilon$ for each side. Strain results were smoothed using a local regression displacement filter on a $3 \times 3$ grid, available within the Dantec software. Results are presented in Table 2.

Tensile modulus values calculated using the larger sized gauges were $1.2 \%$ higher than those from the smaller gauge. Modulus values calculated from Surface 1 were $0.75 \%$ higher than those calculated from Surface 2. The effects due to change in facet overlap were similar on each side and significantly smaller than gauge size and specimen side. In general, the errors calculated for all three variables studied were considered to be insignificant. The larger gauge area was chosen for all subsequent analyses of the composite samples, due to an insignificant increase in computation time. Facet overlap was also minimised to 5 pixels, since it had no distinguishable effect on results for the current application. Using these criteria, the difference in tensile modulus calculated from the 2 surfaces for the steel sample was $0.24 \%$.

\section{Results and Discussion}

\subsection{Global strain variability}

Results are presented for 3 DCFP composites of different thicknesses and two different NCF layups (2 repeats for each fibre architecture). Examples of stress/strain curves for all material types tested are presented in Figure 3. Table 3 shows average tensile modulus values for the composite samples. There is only a small difference (up to $0.6 \%$ maximum) between the modulus values calculated from each side of the NCF samples, the error is generally higher for the DCFP samples (up to $1.8 \%$ maximum) because of larger intra-plaque strain variations 
caused by heterogeneities in the fibre architecture. These can be observed by comparing the full-field Lagrangian strain plots for each composite specimen in Figure 4 to Figure 7. Each figure shows the strain distribution on both sides of the specimen, with white lines indicating where final fracture(s) occurred. Images were taken immediately prior to failure and have been plotted on the same strain scale for easier comparison.

The NCF samples exhibit consistent strain fields on both sides of the specimen at the macro level, with no early indication of where the specimen may fail. There was no distinguishable difference between the strain fields for the two different NCF layups.

In contrast, DIC Images of the DCFP samples show significant variation in the strain field within each surface, consistent with the meso-scale bundle architecture, and also variation in high strain areas between surfaces which appear on one side of the specimen and not the other. This demonstrates the existence of significant local strain gradients, both on the surface and through the thickness of the sample. For the 3mm thick DCFP specimen in Figure 6 for example, the fracture site on surface 1 passes through Point $A$, where there is evidence of a high strain concentration. For the opposing surface 2 , a strain concentration appears $10 \mathrm{~mm}$ lower at point B. On examination of the final failure, the irregular crack is found to pass through both of these strain concentrations (shown by the two white lines in Figure 6), but it is not possible to predict prior to failure whether cracks originating at these two strain concentrations would coalesce to form the final fracture surface. In addition, other regions (Point $\mathrm{C}$ ) contain a number of strain concentrations which by inspection may also form a likely failure plane. For the other samples, large strain concentrations are only visible on one of the two surfaces for both the $6 \mathrm{~mm}$ (Figure 5) and 2mm thick (Figure 7) DCFP samples. This highlights the benefit of observing the surface strains from both sides, as failure initiation sites and events would have been otherwise missed using a conventional DIC setup.

There are fewer prominent strain concentrations in the $2 \mathrm{~mm}$ thick DCFP samples compared with the other thicknesses tested. It is difficult to conclude if this is because of thickness effects, or because the fibre volume fraction is lower $(20 \%)$ and therefore the strain response is dominated more by the matrix material than the fibres. 
1 It is clear from Figure 5 to Figure 7 that the fracture surface intersects at least one of the large

2 strain concentrations identified in the DIC images. The following sections will explore further the

3 cause of these strain concentrations to understand if they are due to surface features, or a

4 result of the internal (sub surface) fibre architecture.

\section{$5 \quad 3.2 \quad$ Local strain variability}

6 Linear strain gauges (approximately $120 \mathrm{~mm}$ long) have been used to quantify the strain

$7 \quad$ variability between the two sides of each composite specimen, presented as strain concentration factors (local strain over global average) for each specimen surface. A single linear gauge was selectively placed through a region of high strain for each sample. Figure 4 summarises the linear gauge data for the two NCF samples. Strains are uniform along the entire length of the gauges in all instances, with a variation within the $\pm 20 \%$ range used in the literature for filtering the effects of noise [34]. The small variation that is evident within the strain patterns appear to have a regular saw tooth form, which resembles the spacing of individual fibres in the fabric. The patterns are consistent on plaques with $0 \% 0^{\circ}$ and $0^{\circ} / 90^{\circ}$ architectures on the outer surfaces, as Figure 4 shows there are horizontal lines of strain variation on both surfaces, despite different surface ply orientations. The DIC detects the influence from the intertow resin rich regions in the ply immediately below the surface.

There are no regions indicating abnormally high strain or that failure could be expected in a particular local area of the NCF sample, even at such high applied strains. Failure was fibre dominated and occurred suddenly at two locations where the radii of the dog bone meets the gauge section, triggered by the stress raiser and the notch sensitive nature of the material [39]. The standard deviation between strain profiles from the two corresponding surfaces, for each specimen, was less than $20 \%$ in each case.

The variation seen in the DCFP linear gauges differs significantly from that of the NCF both along the gauge and between the two corresponding surfaces. The peaks and troughs are irregular in interval and height along the gauge length. For the 3mm thick DCFP sample for example (Figure 6), there are areas where the magnitude of the local strains from the two surfaces are well matched (at a $Y$ distance of $8-22 \mathrm{~mm}$ ), but most areas appear unrelated (for example at $Y=58-65 \mathrm{~mm}$ and $Y=105-110 \mathrm{~mm})$. The standard deviation between the strain profiles 
for Surface 1 and Surface 2 of the $2 \mathrm{~mm}, 3 \mathrm{~mm}$ and $6 \mathrm{~mm}$ thick DCFP samples are $240 \%, 199 \%$ and $91 \%$ respectively. The error clearly reduces as the homogeneity of the sample improves with increasing thickness.

Extreme peaks in the strain distribution are evident at a distance of 6,70 and $112 \mathrm{~mm}$ for the $3 \mathrm{~mm}$ thick DCFP sample (Figure 6). High strains are only recorded on one side of the sample at these points, further demonstrating that local variation in strain can occur across the surface and through the thickness of the specimen. The local strain is 13.5 times higher than the global average at a $Y=70 \mathrm{~mm}$ on Surface 1 , which is the peak value for this particular specimen. However, this point is remote from the final failure point, as fracture occurs due to the high strain observed on Surface 2 at a distance of $Y=6 \mathrm{~mm}(\mathrm{SCF}=10)$.

There is also a single area of high strain on Surface 1 of the $6 \mathrm{~mm}$ thick DCFP specimen (Figure 5) and whilst this is the site of final failure, there is no evidence of a corresponding strain concentration on Surface 2. The local strain at this point $(173 \mathrm{k} \mu \varepsilon)$ is the highest value recorded within any composite specimen and would be consistent with a local fracture or dislocation, since it greatly exceeds the failure strain of the matrix. The magnitude of these local strain concentrations appear to increase with sample thickness, but this can be attributed to the different global strains applied in each case. The strain images were captured just prior to final failure, so the thicker samples were subjected to a higher global strain (see Table 1).

In general, observations for the discontinuous materials are similar to those of Considine and Vahey [40], with extreme levels of strain being identified close to the point of failure. Individual points of high strain, the surface they occur on and their ability to be identified as points of interest are evident at lower levels of applied strain, as shown in Figure 8. However, there are substantially more points with higher than average local strain values, even if viewed with an applied "filtering" method, making it difficult to isolate where the failure will occur. Viewing full field strains on both sides of discontinuous materials ensures that the strain development in the region of ultimate failure is successfully captured, but identifying which of the various high strain regions will trigger final failure is not clear from this method alone. 


\subsection{The influence of bundle ends}

2 The speckle coating was removed from each of the tested specimens and the fibre architecture was compared with the corresponding DIC strain profiles to further understand the cause of the

4 local strain concentrations. An example is shown in Figure 9 using Surface 1 from one of the $3 \mathrm{~mm}$ thick DCFP samples. Both sides of the specimen are similar, with individual fibre bundles and local variations in fibre volume fraction (in the form of resin rich regions) clearly identifiable. The strains in resin rich areas (for example region F) are noticeably higher ( $15000 \mu$ strain) than the globally applied strain $(6900 \mu \varepsilon)$, which is consistent with the lower stiffness expected for a resin dominated area. The highest strain concentrations however, are found to be coincident with bundle ends of fibres directly on the specimen surface. These fibres are orientated in, or close to, the loading direction. This can be clearly seen in regions $C, D$ and $E$ of Figure 9, where strains at the bundle ends of the aligned fibres are significantly higher than those of the surrounding material. Looking at region $\mathrm{D}$ in more detail, Figure 10 shows that the large strain concentration at End 1 is due to a crack developing at the bundle tip. It is well documented in the literature that strain concentrations occur at bundle tips due to filament end synchronisation [21], which can result in significantly lower failure strengths. However, no crack is evident at End 2, demonstrating that the magnitude of the strain concentration is dependent on the underlying fibre architecture

From visual inspections of the samples tested, the largest strain concentrations occur when the tip of a longitudinal bundle coincides with and overlays a transverse bundle. Some additional specimens were manufactured to assess this further, carefully applying fibre bundles at known orientations at the specimen surface. An example is shown in Figure 11, where three longitudinal fibres were placed at the surface in different configurations. Both the top and bottom longitudinal fibres have transverse fibres applied at both ends. The central longitudinal fibre is in isolation, i.e. it is surrounded by the underlying discontinuous material. The magnitude of the strain concentrations at the bundle tips which coincide with a transverse bundle are approaching $50,000 \mu \varepsilon$. The strain concentrations appear to be symmetrical in size and shape for each bundle configuration, as expected. The strain concentrations at the tips of the central bundle are much lower, approximately $25,000-35,000 \mu \varepsilon$. This confirms that the magnitude of the 
strain concentration for surface-based bundles is dependent on the underlying fibre architecture. The final fracture surface for this particular sample coincided with the upper-most strain concentration, which may have also been influenced by the position of the test fixture.

The combination of an aligned (in the direction of loading) bundle end coinciding with a transverse bundle gives rise to the largest strain concentrations measured using the clusterbased DIC system. Large strain concentrations at the tip of the longitudinal bundle, caused by coplanar filament ends, are exacerbated by the low strength of the transverse bundle. The strength of transverse bundles is often quoted to be lower than the strength of the matrix material [41], which in this case causes a crack to initiate in the vicinity of the tip of the longitudinal fibre. The load is transferred from the longitudinal bundle to just a small number of filaments in the transverse bundle through the fibre/matrix interface, causing failure to initiate in the low strength matrix/interface. This propagates as a crack along the length of the transverse bundle. These observations agree with the work of Boursier and Lopez [24] who used a combination of acoustic emission and dye penetrants to show that first cracks tend to initiate at the surface of discontinuous fibre composites. It was also found that these cracks did not always coincide with the final fracture surface. Further work is therefore required to establish if failure can also be initiated by internal features within the fibre architecture, rather than just these surface based defects observed by DIC.

The relationship between the magnitude of these strain concentrations and the relative fibre angle between crossing bundles is not yet known, but has implications in the optimisation of future discontinuous composite materials. Statistically, the number of critical intersections could be controlled through careful choice of fibre length and tow size, minimising the number of bundle ends. In addition, the magnitude of the strain concentration may be managed through bundle end shape, by changing the chopped end from a perpendicular cut to one at 45 degrees, distributing the stress from the longitudinal bundle end to a greater number of filaments in the transverse bundle, as considered in a similar study for single fibre composites [42]. 


\section{Conclusions}

2 Significant variations in surface strain levels were observed in discontinuous carbon fibre bundle composites, which were found to be coincident with critical features in the fibre architecture close to the surfaces of the specimen. The highest strain concentrations were seen to coincide with the ends of fibre bundles aligned with the direction of loading, which overlap transverse bundles. Their magnitude (of over 10) implies that local fracture will occur in the transverse bundle at relatively low global strains, due to the resin-dominated properties of the transverse bundle.

A new multi camera DIC cluster has been used to simultaneously collect full-field strain data from two opposing surfaces of tensile specimens and is shown to be a useful tool for failure analysis. At this stage, final failure cannot be reliably predicted based on strain maps from lowload levels. However there is some evidence to suggest that final failure is driven by coalescence of critical features, which may be able to be determined using a damage mechanics approach.

It is envisaged that further work on characterisation of critical defects and study of crack growth will enable the prediction of failure of discontinuous bundle composites and thus assist engineers to improve the mechanical properties of next generation materials.

\section{Acknowledgements}

This work was conducted as part of the TARF-LCV project funded by the UK Engineering and Physical Sciences Research Council, EPSRC (reference EP/I038616/1). The authors gratefully acknowledge the support of Dantec Dynamics for the development of the multi camera cluster and their technical support throughout this work.

\section{References}

[1] TURNER, T.A., L.T. HARPER, N.A. WARRIOR, and C.D. RUDD, Low cost carbon-fibre based automotive body panel systems - a performance and manufacturing cost comparison. Journal of Automobile Engineering - Proceedings of the Institution of Mechanical Engineers Part D, 2008. 222(1): p. 53-64. 
1 [2] CHAVKA, N.G. and J.S. DAHL. P4 preforming technology development utilizing e-glass and carbon fibers. in SAMPE International Symposium. 1999. Detroit, Michigan. pp 1521

3] HARPER, L.T., T.A. TURNER, N.A. WARRIOR, and C.D. RUDD. Automated preform manufacture for affordable lightweight body structures. in 26th International SAMPE Europe Conference. 2005. Paris. pp

[4] HART-SMITH, L.J., The ten-percent rule for preliminary sizing of fibrous composite structures, in 51st Annual Conference. 1992, Aerospace Materials. p. 10-16.

[5] HALPIN, J.C., Stiffness and expansion estimates for oriented short fiber composites. Journal of Composite Materials, 1969. 3: p. 732-734.

[6] BLUMENTRIT, B.F., B.T. VU, and S.L. COOPER, Mechanical properties of discontinuous fiber reinforced thermoplastics. li. Random-in-plane fibre orientation. Polymer Engineering and Science, 1975. 15(6): p. 428-436.

[7] CHRISTENSEN, R.M. and F.M. WAALS, Effective stiffness of randomly oriented fibre composites. Journal of Composite Materials, 1972. 6: p. 518-532.

[8] MANERA, M., Elastic properties of randomly oriented short fiber-glass composites. Journal of Composite Materials, 1977. 11: p. 235-247.

[9] MISHNAEVSKY, L.L. and P. BRONDSTED, Micromechanical modelling of strength and damage of fiber reinforced composites. 2007, Technical University of Denmark: Riso National Laboratory.

[10] COX, H.L., The elasticity and strength of paper and other fibrous materials. British Journal of Applied Physics, 1952. 3: p. 72-79.

[11] ZHOU, X.F. and H.D. WAGNER, Stress concentrations caused by fiber failure in twodimensional composites. Composites Science and Technology, 1999. 59(7): p. 10631071.

[12] NAYFEH, A.H., Thermomechanically induced interfacial stresses in fibrous composites. Fibre Science and Technology, 1977. 10(3): p. 195-209.

[13] HEUVEL, v.d. and et al, Failure phenomena in fibre reinforced composites. Part 6: A finite element study of stress concentrations in unidirectional carbon fibre-reinforced epoxy composites. Composites Science and Technology, 2004. 64: p. 645-656. 
1 [14] NEDELE, M.R. and M.R. WISNOM, Three-dimensional finite element analysis of the stress concentration at a single fibre break. Composites Science and Technology, 1994. 51(4): p. 517-524.

[15] PAN, Y., L. IORGA, and A.A. PELEGRI, Analysis of 3d random chopped fiber reinforced composites using fem and random sequential adsorption. Computational Materials Science, 2008. 43(3): p. 450-461.

[16] HARPER, L.T., C. QIAN, T.A. TURNER, S. LI, and N.A. WARRIOR, Representative volume elements for discontinuous carbon fibre composites - part 1: Boundary conditions. Composites Science and Technology, 2012. 72(2): p. 225-234.

[17] HARPER, L.T., C. QIAN, T.A. TURNER, S. LI, and N.A. WARRIOR, Representative volume elements for discontinuous carbon fibre composites - part 2: Determining the critical size. Composites Science and Technology, 2012. 72(2): p. 204-210.

[18] BROCKENBOROUGH, J.R., S. SURESH, and H.A. WIENECKE, Deformation of metalmatrix composites with continuous fibers: Geometrical effects of fiber distribution and shape. 1991, Acta Metall.Mater. p. 735-752.

[19] HOLLAWAY, L.C. and P.R. HEAD, in Advanced polymer composites and polymers in the civil infrastructure, L.C.H.R. Head, Editor. 2001, Elsevier Science Ltd: Oxford.

[20] LINDHAGEN, J.E. and L.A. BERGLUND, Microscopical damage mechanisms in glass fiber reinforced polypropylene. Journal of Applied Polymer Science, 1998. 69(7): p. 1319-1327.

[21] PIGGOTT, M.R., Mesostructures and their mechanics in fibre composites. Advanced Composite Materials, 1996. 6: p. 75-81.

[22] HARPER, L.T., T.A. TURNER, N.A. WARRIOR, and C.D. RUDD, Characterisation of random carbon fibre composites from a directed fibre preforming process: The effect of tow filamentisation. Composites: Part A: Applied Science and Manufacturing, 2007. 38(3): p. 755-770.

[23] CHOI, N.S. and K. TAKAHASHI, Stress fields on and beneath the surface of short-fiberreinforced composites and their failure mechanisms. Composites Science and Technology, 1992. 43(3): p. 237-244. 
[24] BOURSIER, B. and A. LOPEZ. Failure initiation and effect of defects in structural discontinuous fibre composites. in Fall Technical Conference. 2010. Salt Lake City: SAMPE. pp

[25] GREDIAC, M., The use of full-field measurement methods in composite material characterization: Interest and limitations. Composites: Part A, 2004. 35: p. 751-761.

[26] GOIDESCU, C., H. WELEMANE, C. GARNIER, M. FAZZINI, R. BRAULT, E. PERONNET, and S. MISTOU, Damage investigation in cfrp composites using full-field measurement techniques: Combination of digital image stereo-correlation, infrared thermography and x-ray tomography. Composites Part B: Engineering, 2013. 48: p. 95105.

[27] CHU, T.C., W.F.RANSON, M.A.SUTTON and W.H.PETERS, Applications of digitalimage-correlation techniques to experimental mechanics. Experimental Mechanics, 1985. 25(3): p. 232-244.

[28] HELM, J.D., M.A.SUTTON, and S.R.MCNEILL. Three dimensional image correlation for surface displacement measurement. in SPIE Videometrics III. 1994. pp 32-45

[29] HELM, J.D., S.R.McNEILL and M.A.SUTTON, Improved three dimensional image correlation for surface displacement measurement. Optical Engineering, 1996. 35(7): p. 1911-1920.

[30] SUTTON, M.A., W.J.WOLTERS, W.H.PETERS, W.F.RANSON and S.R.McNEILL, Determination of displacements using an improved digital image correlation method. Image and Vision Computing, 1983. 1(3): p. 133-139.

[31] BING, P., K.QIAN, H.XIE and A.ASUNDI, Two-dimensional digital image correlation for in-plane displacement and strain measurement: A review. Measurement Science and Technology, 2009. 20(062001): p. 17.

[32] LAVA.P, VAN.PAEPEGEM.W, COPPIETERS.S, D. BAERE.I, WANG.Y, and DEBRUYNE.D, Impact of lens distortions on strain measurements obtained with $2 d$ digital image correlation. Optics and Lasers in Engineering, 2013. 51(5): p. 576-584.

[33] FERABOLI, P., T. CLEVELAND, M. CICCU, P. STICKLER, and L. DEOTO, Defect and damage analysis of advanced discontinuous carbon/epoxy composite materials. Composites: Part A. Applied Science and Manufacturing, 2010. 41(6 ): p. 774-786. 
[34] FERABOLI, P., T. CLEVELAND, P. STICKLER, and J. HALPIN, Stochastic laminate anology for simulating the variability in modulus of discontinuous composite materials. Composites: Part A, 2010. 41: p. 557-570.

[35] LAURIN, F., J.-S CHARRIER, D.LEVEQUE, J.-F MAIRE, A.MAVEL, P.NUNEZ, Determination of the properties of composite materials thanks to digital image correlation measurements. Procedia IUTAM, 2012. 4: p. 106-115.

[36] De ALMEIDA, O., F. LAGATTU, and J. BRILLAUD, Analysis by a 3d dic technique of volumetric deformation gradients: Application to polypropylene/epr/talc composites. Composites Part A: Applied Science and Manufacturing, 2008. 39(8): p. 1210-1217.

[37] HARPER, L.T., T.A. TURNER, N.A. WARRIOR, J.S. DAHL, and C.D. RUDD, Characterisation of random carbon fibre composites from a directed fibre preforming process: Analysis of microstructural parameters. Composites Part A: Applied Science and Manufacturing, 2006. 37(11): p. 2136-2147.

[38] QIAN, C., L.T.HARPER, T.A.TURNER and N.A.WARRIOR, Notched behaviour of discontinuous carbon fibre composites; comparison with quasi-isotropic non-crimp fabric. Composites Part A: Applied Science and Manufacturing, 2011. 42(3): p. 239-302.

[39] EDGREN, F., C. SOUTIS, and E.A. LEIF, Damage tolerance analysis of ncf composite sandwich panels. Composite Science and Technology, 2008. 68(13): p. 2635-2645.

[40] CONSIDINE, J.M., D.W.VAHEY. Full-field local displacement analysis of two-sided paperboard. in 61st Appita Annual Conference and Exhibition. 2007. Gold Coast. pp

[41] SODEN, P.D., M.J. HINTON, and A.S. KADDOUR, Lamina properties, lay-up configurations and loading conditions for a range of fibre-reinforced composite laminates. Composites Science and Technology, 1998. 58(7): p. 1011-1022.

[42] MacLAUGHLIN, T., Effect of fiber geometry on stress in fiber-reinforced composite materials. Experimental Mechanics, 1966. 6(10): p. 481-492. 
3 Table 1: Target fibre volume fraction (Vf), target thickness ( $t$ ) and summary of average 4 tensile modulus, UTS and global strain values for each plaque

5

\begin{tabular}{cccccccc}
\hline Plaque & Architecture & $\begin{array}{c}\text { Fibre Areal } \\
\text { Mass }(\mathrm{gsm})\end{array}$ & $\begin{array}{c}\text { Target } \\
\mathrm{Vf}(\%)\end{array}$ & $\begin{array}{c}\text { Target } \\
\mathrm{t}(\mathrm{mm})\end{array}$ & $\begin{array}{c}\mathrm{E} \\
(\mathrm{GPa})\end{array}$ & $\begin{array}{c}\text { UTS } \\
(\mathrm{MPa})\end{array}$ & $\begin{array}{c}\text { Global } \varepsilon_{\text {failure }} \\
(\mu \varepsilon)\end{array}$ \\
\hline $\mathrm{A}$ & $\mathrm{NCF}_{1}$ & 2400 & 40 & 3 & 51.0 & 597 & 11121 \\
$\mathrm{~B}$ & $\mathrm{NCF}_{2}$ & 2400 & 40 & 3 & 51.2 & 656 & 12325 \\
$\mathrm{C}$ & $\mathrm{DCFP}$ & 800 & 20 & 2 & 9.5 & 67 & 6209 \\
$\mathrm{D}$ & $\mathrm{DCFP}$ & 2400 & 40 & 3 & 24.8 & 149 & 6941 \\
$\mathrm{E}$ & $\mathrm{DCFP}$ & 4800 & 40 & 6 & 21.8 & 162 & 8326
\end{tabular}

6

Table 2: Tensile modulus (GPa) for steel sample. Calculated using rectangular polygon gauges with different facet overlaps (5, 9, 12 pixels) and different lengths (large $=120 \mathrm{~mm}$, small $=50 \mathrm{~mm}$ ).

\begin{tabular}{lcccccc}
\hline Facet Overlap & \multicolumn{2}{c}{5} & \multicolumn{2}{c}{9} & \multicolumn{2}{c}{12} \\
\hline Gauge Size & Large & Small & Large & Small & Large & Small \\
\hline Side 1 & 194.4 & 192.1 & 193.5 & 192.0 & 194.1 & 192.1 \\
Side 2 & 193.5 & 190.3 & 193.0 & 189.9 & 192.3 & 190.6 \\
Average & 194.0 & 191.2 & 193.3 & 191.0 & 193.2 & 191.4 \\
Std dev & & & & & & \\
between & 0.24 & 0.48 & 0.12 & 0.57 & 0.47 & 0.39 \\
side 1\&2 (\%) & & & & & & \\
\hline
\end{tabular}

Table 3: Tensile modulus (GPa) for composite samples

\begin{tabular}{|c|c|c|c|c|c|c|c|c|c|c|}
\hline Composite & \multicolumn{2}{|c|}{$\mathrm{NCF}_{1}$} & \multicolumn{2}{|c|}{$\mathrm{NCF}_{2}$} & \multicolumn{2}{|c|}{ 2mm DCFP } & \multicolumn{2}{|c|}{ 3mm DCFP } & \multicolumn{2}{|c|}{$6 \mathrm{mmDCFP}$} \\
\hline Sample & 1 & 2 & 1 & 2 & 1 & 2 & 1 & 2 & 1 & 2 \\
\hline Side 1 & 51.8 & 50.9 & 50.6 & 51.3 & 11.1 & 7.6 & 26.0 & 23.8 & 21.8 & 21.1 \\
\hline Side 2 & 51.8 & 50.3 & 51.0 & 51.1 & 11.5 & 7.6 & 25.6 & 23.8 & 22.6 & 21.5 \\
\hline $\begin{array}{l}\text { Average } \\
\text { Std dev }\end{array}$ & 51.8 & 50.6 & 50.8 & 51.2 & 11.3 & 7.6 & 25.8 & 23.8 & 22.2 & 21.3 \\
\hline $\begin{array}{c}\text { between } \\
\text { side 1\&2 (\%) }\end{array}$ & 0.0 & 0.59 & 0.39 & 0.20 & 1.77 & 0.0 & 0.78 & 0.0 & 1.80 & 0.94 \\
\hline
\end{tabular}




\section{Figures}

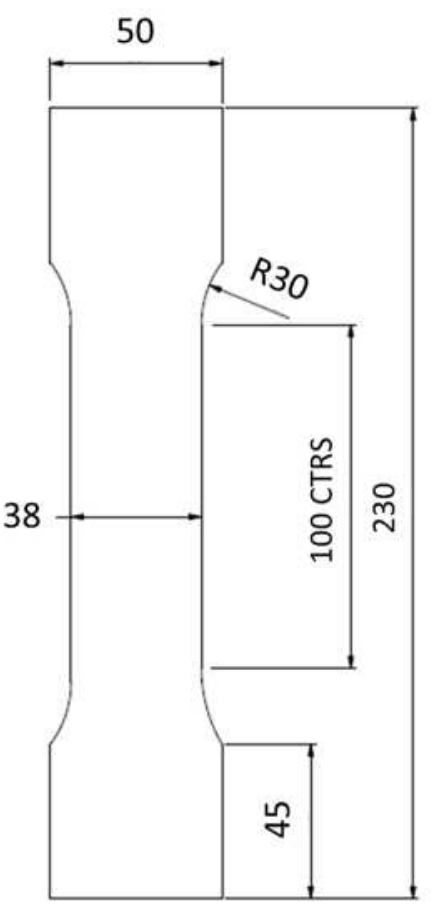

Figure 1: Dog bone dimensions (in $\mathrm{mm}$ )

4

5

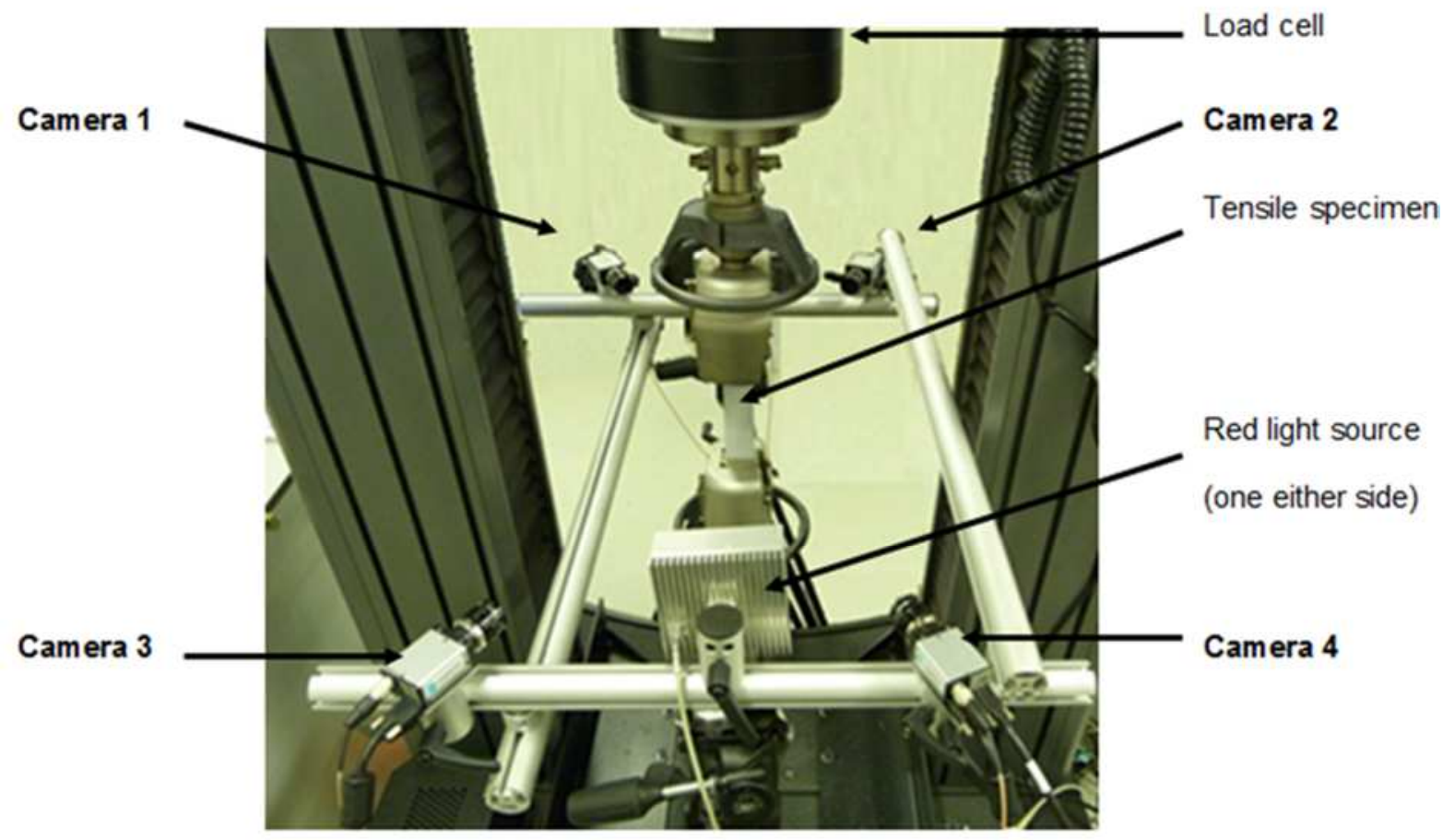

6 Figure 2: Multi Camera DIC System setup 


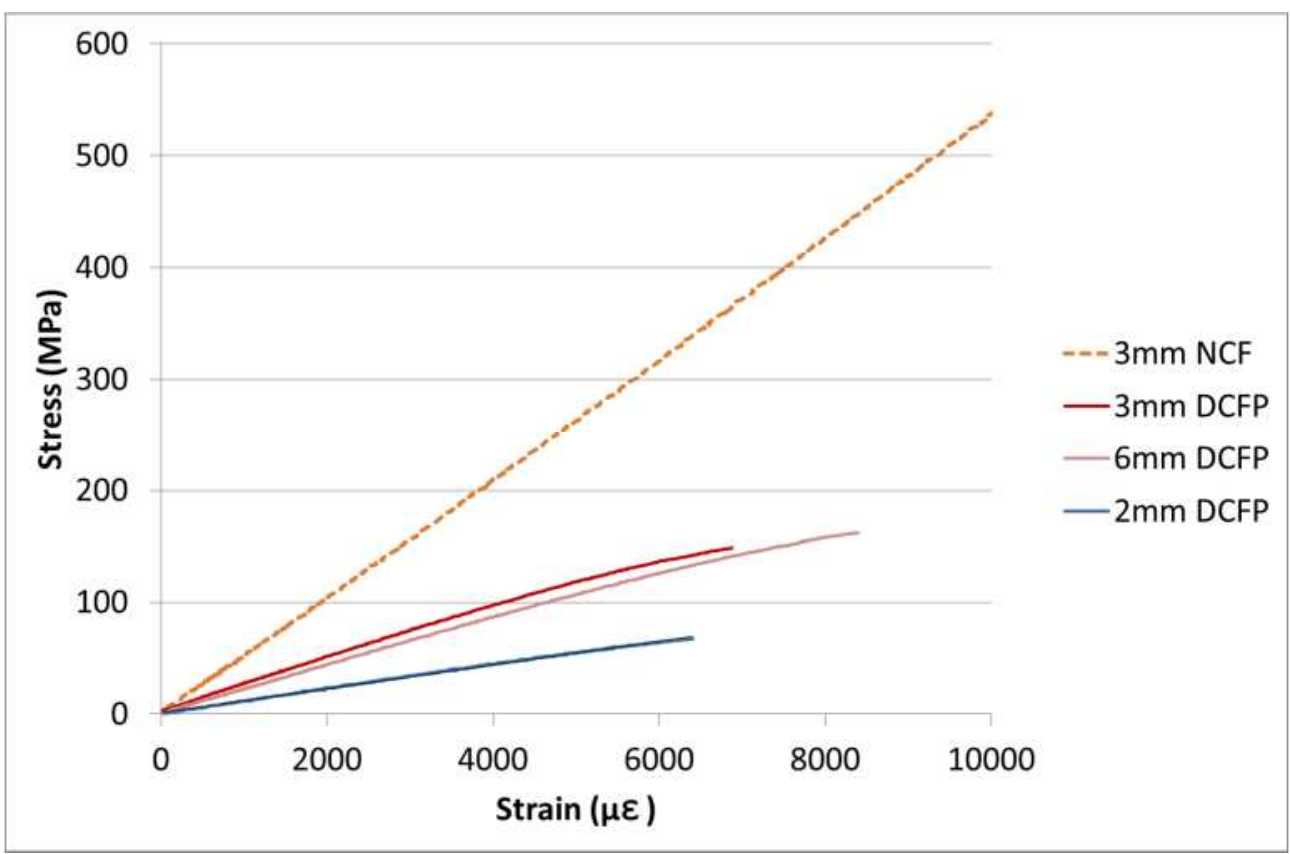

3 Figure 3: Typical Stress/Strain curves for composite materials studied.

4

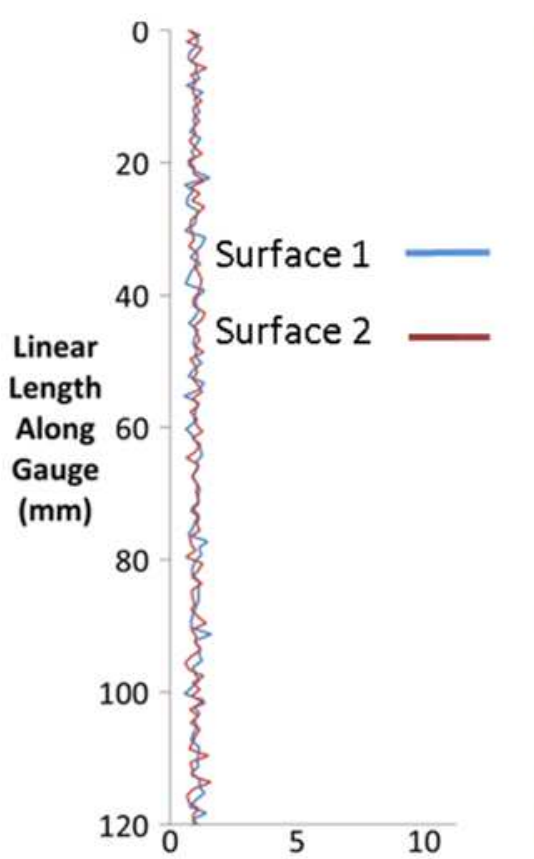

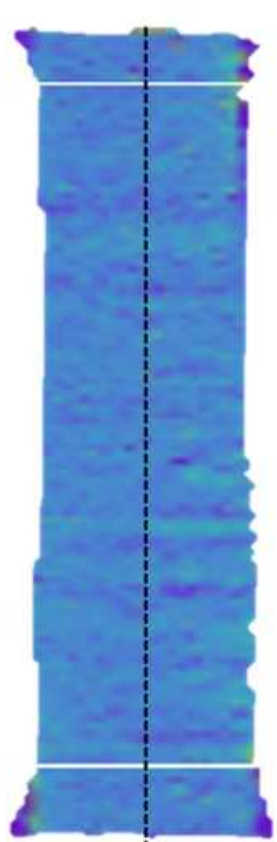

Strain Concentration Surface 1

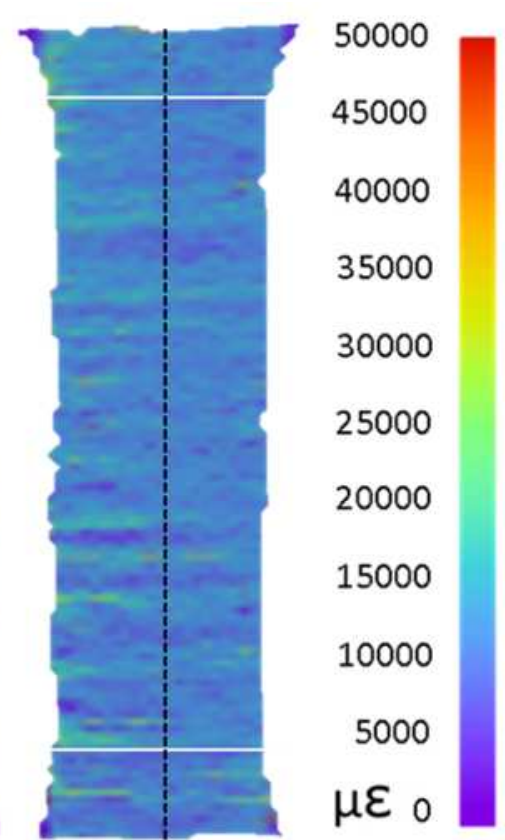

Surface 2
5

7

8

9

\section{Factor}

Figure 4: Lagrangian full field strain plot for $3 \mathrm{~mm}$ thick $\mathrm{NCF}_{1}$ sample. Approximate plane of failure indicated by white line. Linear gauge position indicated by dotted line. Applied global strain - 11121 ustrain. 


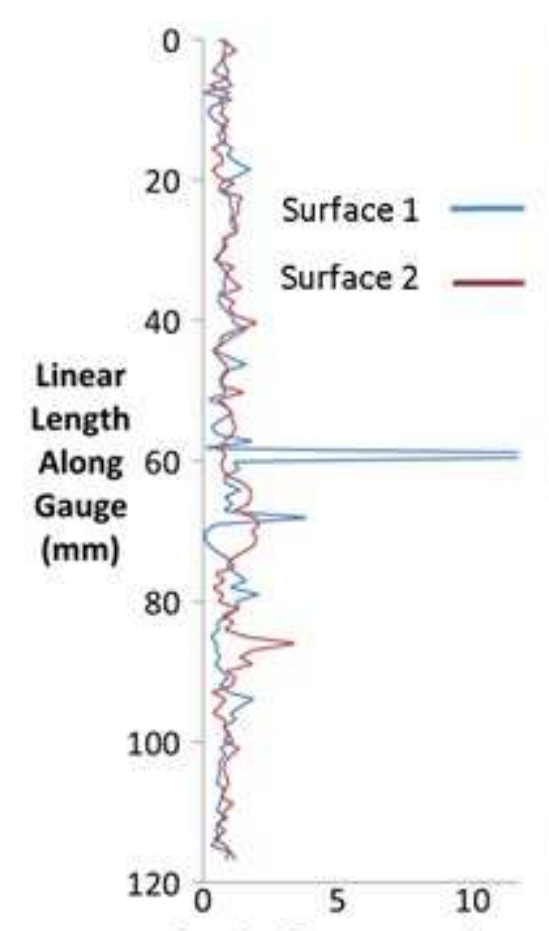

Strain Concentration

Factor

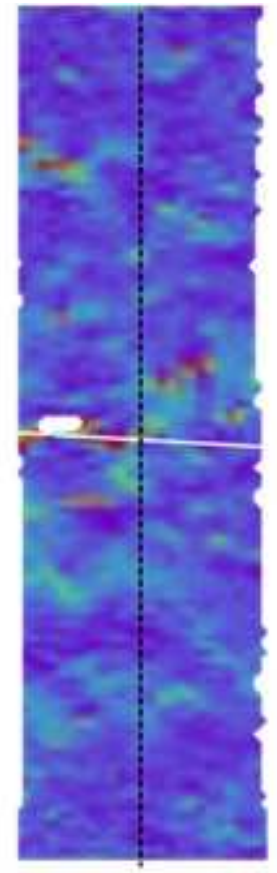

Surface 1

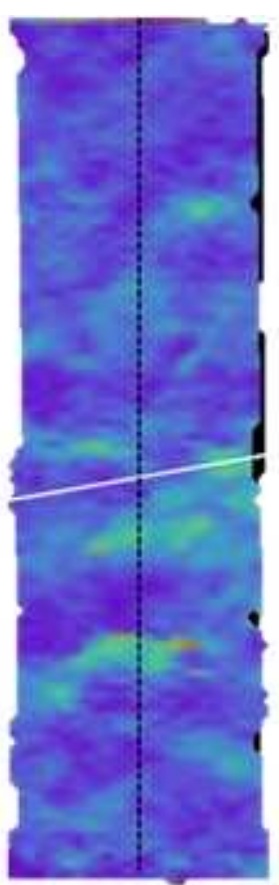

Surface 2

50000

45000

40000

35000

30000

25000

20000

15000

10000

5000

$\mu \varepsilon$ 。

1

Figure 5: Lagrangian full field strain plot for $6 \mathrm{~mm}$ thick DCFP sample. Approximate plane of failure indicated by white line. Linear gauge position indicated by dotted line. Applied global strain $8326 \mu$ strain.

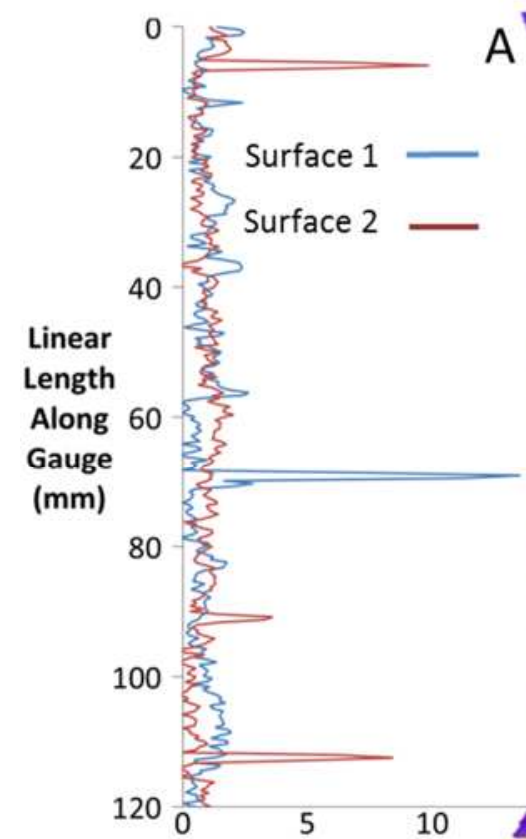

Strain Concentration

Factor

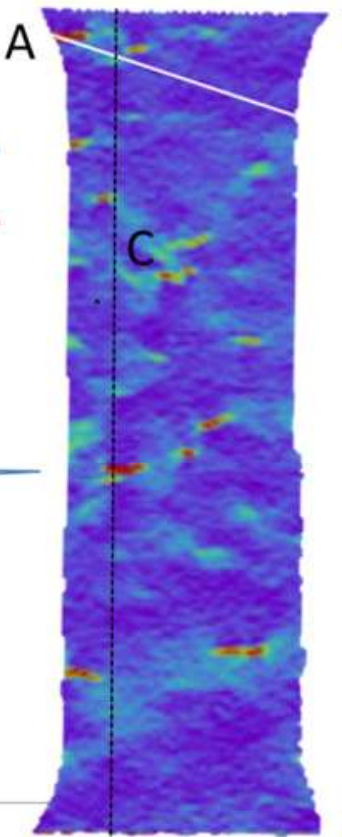

Surface 1

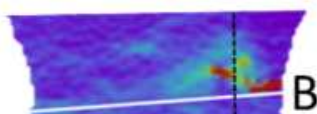

50000

45000

40000

35000

30000

25000

20000

15000

10000

5000

$\mu \varepsilon_{0}$

Figure 6: Lagrangian Full Field Strain Plot for 3mm thick DCFP sample. Approximate plane of failure indicated by white line. Linear gauge position indicated by dotted line. Applied global strain $6941 \mu$ strain. 


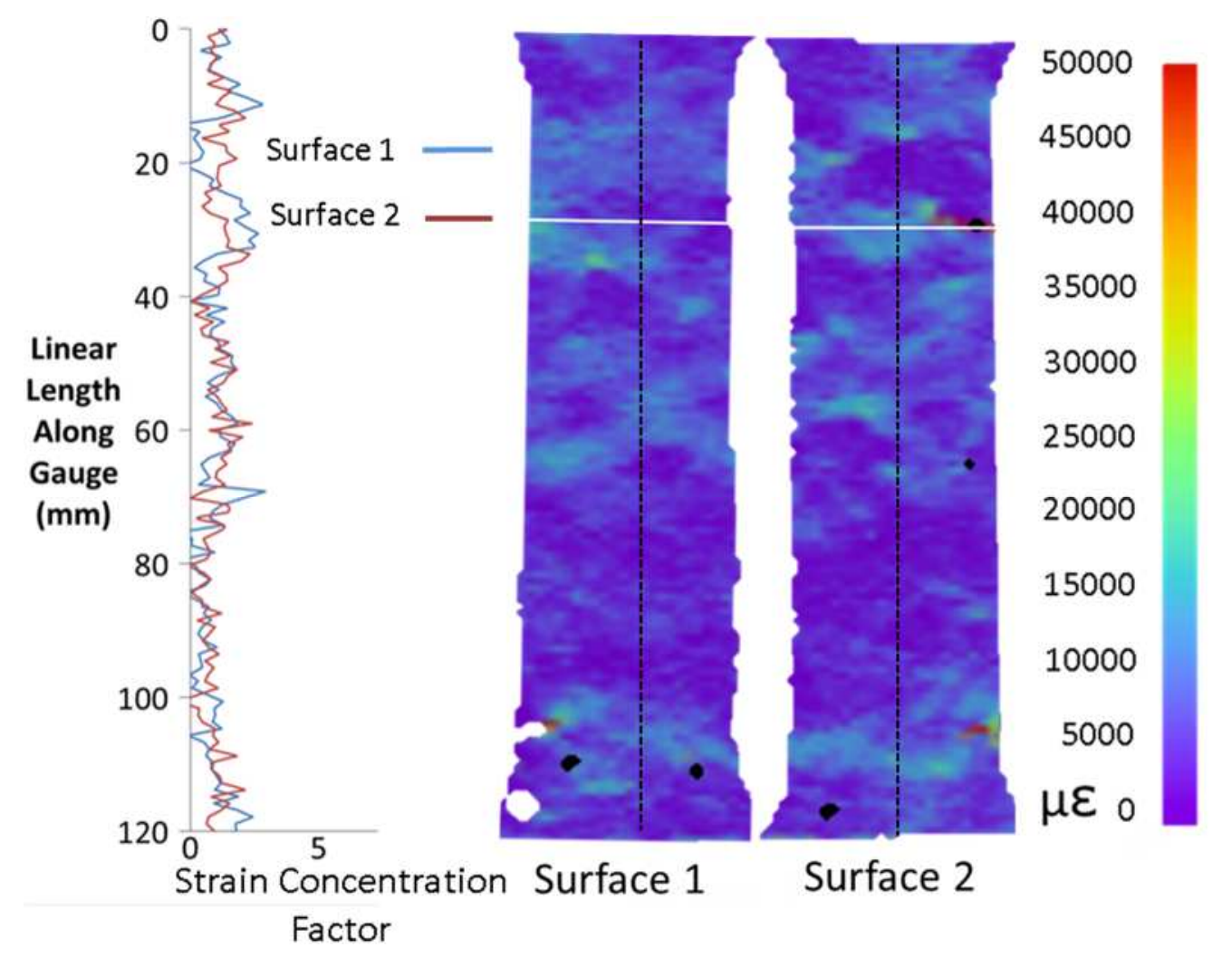

Figure 7: Lagrangian full field strain plot for $2 \mathrm{~mm}$ thick DCFP sample. Approximate plane of failure indicated by white line. Linear gauge position indicated by dotted line. Applied global strain 6209 ustrain.

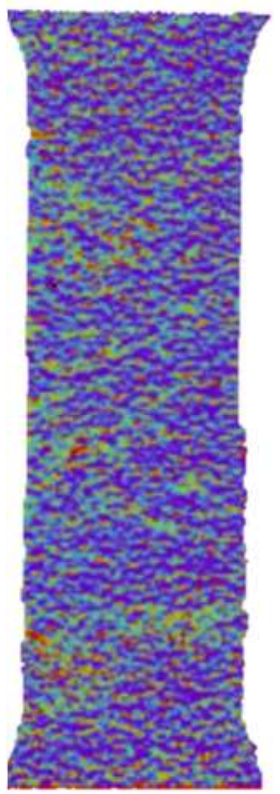

5000
4500
4000
3500
3000
2500
2000
1500
1000
500
$\mu \varepsilon 0$
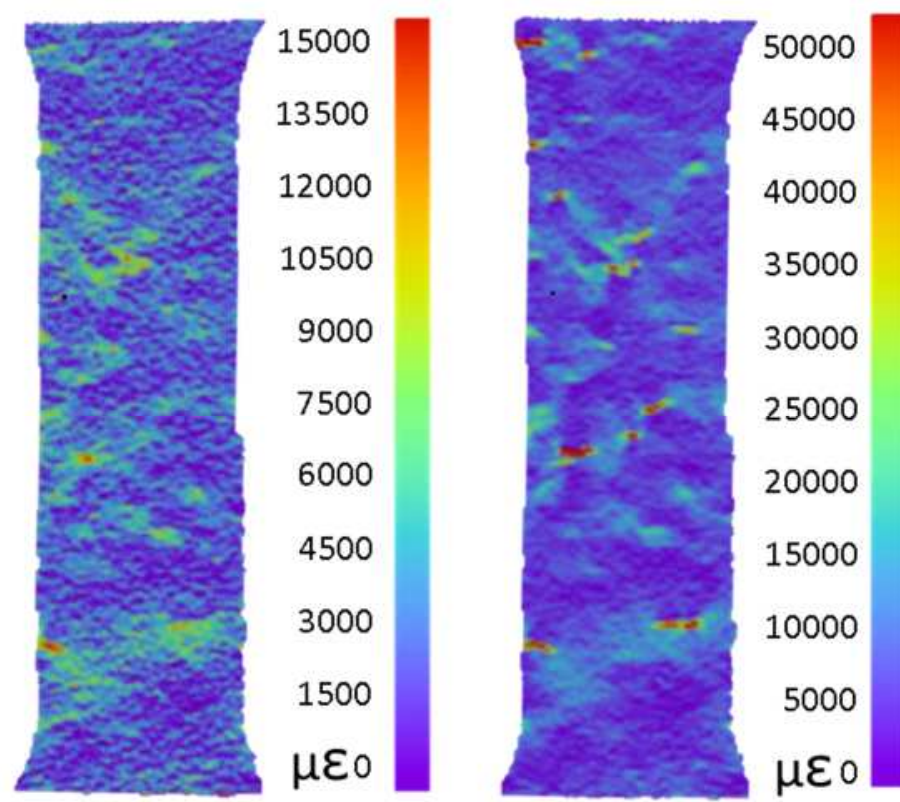

6

Figure 8: Lagrangian strain profile for Surface 1 from $3 \mathrm{~mm}$ thick DCFP sample at global applied strain of (Left) $1000 \mu$ strain, (centre) $3000 \mu$ strain and (right) $6900 \mu$ strain . 


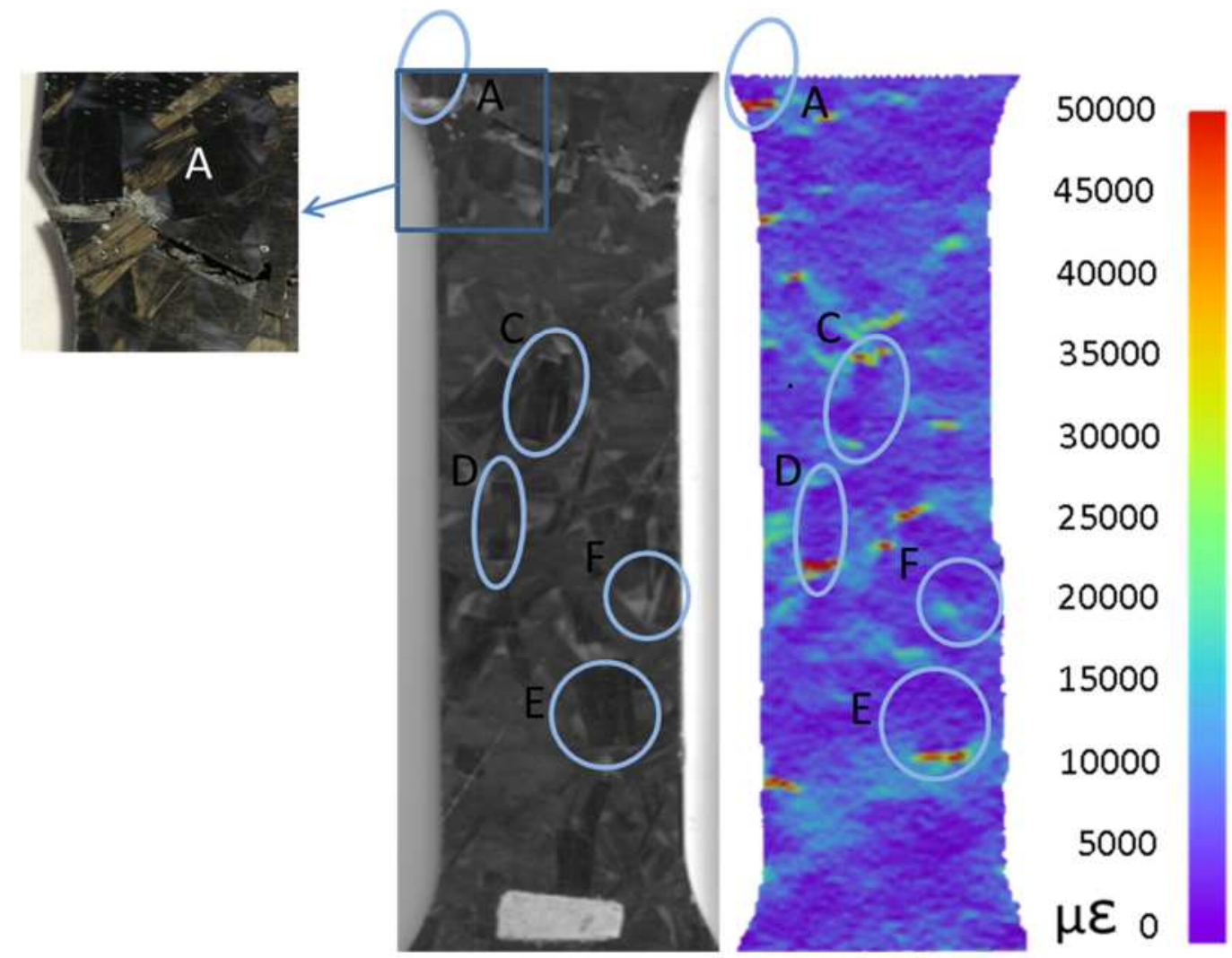

Figure 9: Comparison of strain distribution and an image showing the surface fibre architecture for $3 \mathrm{~mm}$ DCFP Surface 1 . Inset image shows an aligned fibre bundle end coincident with strain concentration and final failure 


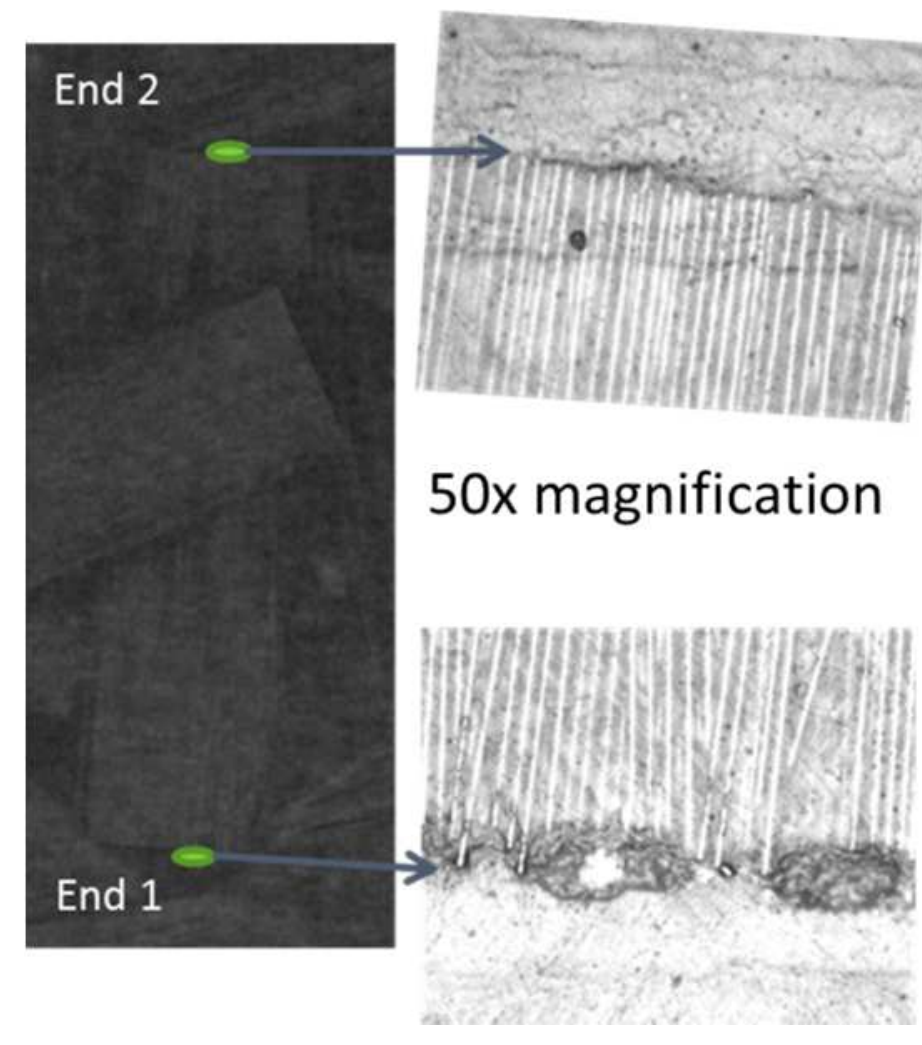

2 Figure 10: Surface image taken from region $D$ in Figure 9. The micrograph images 3 indicate that a crack has formed at End 1 only. 


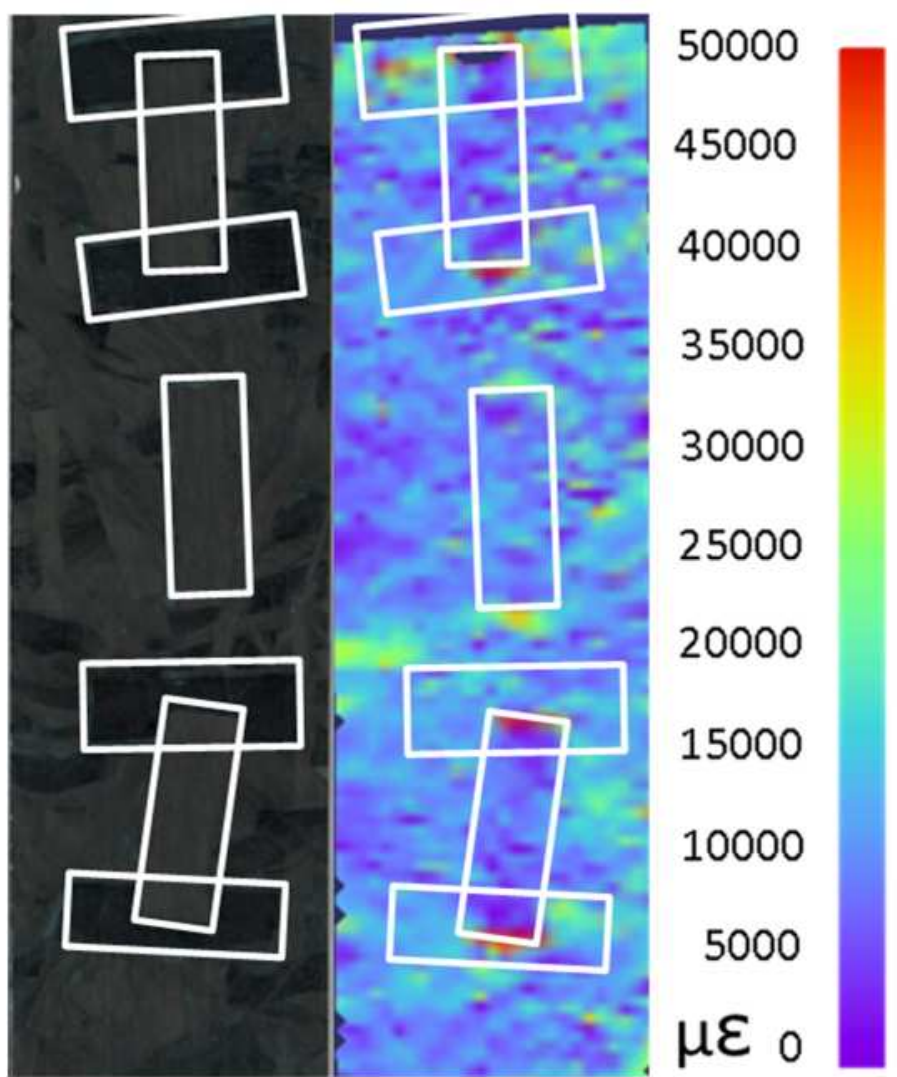

2

Figure 11: DIC strain field showing the consequence of bundle ends on the magnitude of strain concentrations. Strain concentrations are the highest when the bundle end coincides with a transverse fibre. 